\title{
Comparative Studies on the Chemo and Biosynthesized Nanomaterials for the Remediation of Pharmaceutical Residues in Wastewater
}

\author{
C. M. Ngwu ${ }^{1 *}$, J. C. Nnaji ${ }^{1}$, S. O. Odoemelam ${ }^{1}$ and F. J. Amaku ${ }^{1}$ \\ ${ }^{1}$ ChemistryDepartment, Michael Okpara University of Agriculture Umudike, P.M.B 7267 \\ Umuahia, Abia State, Nigeria \\ *Corresponding Author: kom4tngwu@gmail.com, +2348032145757 \\ Received 13 August 2020; accepted 05 September 2020, published online 10 October 2020
}

\begin{abstract}
In the present study, comparison was made on the wastewater remediation efficiencies of chemically and biologically synthesized magnetite and zinc oxide nanoparticles. Starchytarpheta indica (snake weed) leaf extract was used as a reducing and capping agent in the green synthesis of magnetite and zinc oxide. The synthesized nanoparticles (NPs) were characterized by X-ray diffraction studies (XRD), Field emission scanning electron microscopy (FESEM) and Fourier transform infra-red spectroscopy (FTIR). These synthesized nanoparticles were further applied in the treatment of industrial pharmaceutical effluent basically comprising amoxicillin, acetaminophen and ascorbic acid. The NPs all performed differently in the removal of these pharmaceutical active compounds. Results showed that the NPs had significant removal efficiencies for acetaminophen, ranging from $67.07 \%-93.59 \%$, with bio-ZnO having the highest removal efficiency and magnetite giving the least. The range of removal efficiency for ascorbic acid was $54.35 \%-100 \%$, Magnetite and bio-magnetite showed the highest removal efficiencies whereas bio- $\mathrm{ZnO}$ had the least removal rate. Wastewater treatment for the removal of amoxicillin residues with the synthesized nanoparticles was not quite significant, negative removal patterns were observed for wastewater treatment with bio- $\mathrm{ZnO}$ and magnetite, a removal rate of $16.82 \%$ was obtained for treatment with bio-magnetite, $\mathrm{ZnO}$ NPs had the highest removal efficiency of $49.73 \%$. Generally, $\mathrm{ZnO}$ and biomagnetite NPs displayed better removal capacities than the other NPs, with overall removal rates of 64.71 $\%$ and $48.92 \%$ for $\mathrm{ZnO}$ and bio-magnetite NPs respectively.
\end{abstract}

Keywords: Nanoparticles, pharmaceutical residues, remediation, wastewater treatment

\section{Introduction}

The continuous discharge of industrial wastewater into the environment has brought about the release of contaminants of concern such as pharmaceutically active compounds (PhACs) in the aquatic environment. There is global concern that the existence of these contaminants in the environment may lead to adverse human and ecological health effects prompted by their high solubility in water [1] Numerous pharmaceutically active compounds are found in concentrations of parts per billion or trillion in water bodies. This quantity although minute is sufficient to harm the environment and aquatic life. PhACs are also labeled as hormone disrupters, this implies that these contaminants comprises synthetic hormones, (e.g, estrogen or androgen), which when ingested, can meddle with the normal hormonal processes in animals or humans [2]. $\mathrm{PhAC}$ have been discovered to cause infertility, delayed reproductive development, kidney and liver damage in animals. Synthetic estrogen, present in PhACs has been found to cause hormone interruption in fish, bringing about the feminization of male fish [4].

Apart from industrial discharge and wastewater treatment plants, pharmaceutically active compounds also enter the environment through excretion of drugs taken by humans and animals as inactivated conjugated metabolites of the parent compound. They can also accidentally enter the water supply during manufacturing, handling, and storage. Various manufacturing industries seldom treat their effluents before discharging them into waterbodies, and most WWTPs are not equipped to effectively remove pharmaceutical active compounds from wastewater [5], hence the need for effective treatment method that will remove these contaminant at source before being discharged into the environment. 
The potentials of nanoadsorbents such as magnetite and zinc oxide can be harnessed for the treatment of industrial effluents, because of their cost effectiveness and high efficiency in the removal of pollutants. Furthermore, their high surface area-to-volume ratio increases their reactivity with environmental contaminants [6]. These nanoparticles can be synthesized either chemically or biologically, and efforts are being made to make them more environmentally friendly, hence the biological synthesis.

In this study, chemical and biological synthesis methods were employed for the preparation of magnetite and zinc oxide nanoparticles. The leaves extracts of Stachytarpheta indica (snake weed) was used for the biological synthesis of both metal oxide nanoparticles. The synthesized nanoparticles were characterized using; FESEM, XRD and FTIR. Finally the nanoparticles were applied as potential adsorbents for the treatment of industrial pharmaceutical effluent, and a comparison was made on their removal efficiencies.

\section{Materials and method \\ Chemicals}

All chemicals, standards and reagents were analytical grade and of highest purity. They include: HPLC grade; Acetonitrile, methanol, water, monobasic sodium phosphate, phosphoric acid, sodium hydroxide, edetate disodium dehydrate, monobasic potassium phosphate. Standards which are chemically similar to the target compounds include; amoxicillin RS (USP), acetaminophen RS (USP), and ascorbic acid RS (USP). These were all supplied by Mereck (Germany). Others are: Zinc acetate dihydrate, $\mathrm{Zn}\left(\mathrm{CH}_{3} \mathrm{COO}\right)_{2} 2 \mathrm{H}_{2} \mathrm{O}(\mathrm{BDH})$; sodium carbonate $\mathrm{Na}_{2} \mathrm{CO}_{3}(\mathrm{BDH})$, Ethanol $\left(\mathrm{C}_{2} \mathrm{H}_{5} \mathrm{OH}\right)$ (Sigma-Aldrich), iron (III) chloride hexahydrate $\left(\mathrm{FeCl}_{3} \cdot 6 \mathrm{H}_{2} \mathrm{O}\right)$, iron (II) chloride tetrahydrate $\left(\mathrm{FeCl}_{2} \cdot 4 \mathrm{H}_{2} \mathrm{O} \geq 99 \%\right)$, acetic acid, sodium hydroxide, and $25 \%$ ammonia solution were all purchased from BDH Chemicals Limited, Poole, England. Stachytarpheta indica leaves (Michael Okpara University of Agriculture, Umudike).

\section{Adsorbents preparation}

Chemical synthesis of Zinc Oxide $(\mathrm{ZnO})$ nanoparticles

$\mathrm{ZnO} \mathrm{NP}$ was prepared by the precipitation method according to Fouad et al., (2011) [7] and
Mohamed et al., (2012) [8], with slight modification.

\section{Biosynthesis of $\mathrm{ZnO}$ nanoparticles}

The leaves samples were thoroughly washed with clean water and rinsed with distilled water. The leaves were allowed to dry at room temperature and $20 \mathrm{~g}$ was taken for synthesis purpose. The weighed leaves were boiled with $100 \mathrm{~mL}$ of distilled water for $20 \mathrm{~min}$ at $60{ }^{\circ} \mathrm{C}$. The light yellow coloured solution formed was left to cool. After that, the solution was filtered, and used for the biosynthesis. The biosynthesis of $\mathrm{ZnO}$ nanoparticle was carried out using the methods described by Sangeetha et al. (2011) [9] and Gnanasangeetha and Thambavani (2013) [10].

Preparation of magnetite nanoparticles (M.NPs.)

Chemical precipitation method as described by Khalil (2015) [11] was employed in the synthesis of magnetite nanoparticles.

\section{Biosynthesis of magnetite nanoparticles}

S. indica/ $\mathrm{Fe}_{3} \mathrm{O}_{4}-\mathrm{NPs}$, was synthesized using the following procedure; Firstly, a solution of $\mathrm{Fe}^{3+}$ and $\mathrm{Fe}^{2+}$ salts in a $2: 1 \mathrm{M}$ ratio was added to the snakeweed extract $(50 \mathrm{~mL})$ to obtain a yellowish colloidal solution. Then, a freshly prepared 1.0 M solution of $\mathrm{NaOH}$ was added drop-wise to the solution under continuous stirring. The $\mathrm{pH}$ of the solution was adjusted to 11 , and the solution was then stirred for $1 \mathrm{~h}$ to allow complete homogenization. The biomagnetite nanoparticles formed was washed severally with deionized water and dried in an oven at $70{ }^{\circ} \mathrm{C}$ for $24 \mathrm{~h}$ and stored for further use.

\section{Instrumentation}

X-ray diffraction (XRD) patterns and crystallography of the synthesized nanoparticles were recorded using a high-resolution Bruker D8 Advance diffractometer of $\mathrm{Cu} \mathrm{K \alpha}(\lambda=$ $1.54050 \AA$ ) radiation. Morphologies of synthesized nanoparticles were studied using Field emission scanning electron microscopy equipped with an energy dispersive X-ray (EDX) detector (FESEM) (ZEISS ultra plus). Infrared spectra and structural arrangement were obtained by using a Fourier transform infrared spectrometer (FTIR) (Perkin-Elmer Spectrum $\mathrm{RX} 1)$. Concentrations of the pharmaceutical compounds in the effluent were carried out 
quantitatively, using a Hitachi HPLC UV-VIS detector with Elite Lachrom software.

Treatment of pharmaceutical wastewater with NPs

The synthesized NPs were further applied to industrial pharmaceutical effluents to test their removal efficiencies of some drug residues. The wastewater samples were gotten from the effluents of the penultimate and final washings and cleaning of the entire production line for the day's production. Effluent Samples collected after each washing phase was pooled together, the $\mathrm{pH}$ was measured, and sample was stored at $4{ }^{\circ} \mathrm{C}$. Triplicate analysis of the effluent was done using HPLC/UV to measure the initial concentrations of drug residues in the effluent samples at $\mathrm{pH}$ of 5.5, which was the $\mathrm{pH}$ of the effluent sample. The synthesized nanoparticles ( $\mathrm{ZnO}$, bio-ZnO, magnetite, and bio-magnetite) (I g) were then separately added to the effluent sample and were agitated in a fixed speed rotator for a minimum of $180 \mathrm{~min}$. at $400 \mathrm{rpm}$. At the end of the contact time, the samples were filtered and analyzed with HPLC. The percentage removal $(\% \mathrm{R})$ was determined using:

$$
\% \mathrm{R}=\frac{\mathrm{Co}-\mathrm{Ce}}{\mathrm{Co}} \boldsymbol{X} 100
$$

Table1 Chromatographic conditions

\begin{tabular}{|c|c|c|c|}
\hline Conditions & Acetaminophen & Amoxicillin & $\begin{array}{l}\text { Ascorbic } \\
\text { acid }\end{array}$ \\
\hline mode & $\mathrm{LC}$ & $\mathrm{LC}$ & LC \\
\hline $\begin{array}{l}\text { UV } \\
\text { detector } \\
\text { wavelength }\end{array}$ & $243 \mathrm{~nm}$ & $261 \mathrm{~nm}$ & $245 \mathrm{~nm}$ \\
\hline $\begin{array}{l}\text { Stationary } \\
\text { phase } \\
\text { (column) }\end{array}$ & $\begin{array}{l}3.9 \mathrm{~mm} \times 30 \\
\mathrm{~cm} \text {; packing L1 }\end{array}$ & $\begin{array}{l}4 \mathrm{~mm} \times 30 \\
\mathrm{~cm} ; 3 \text { to } 10 \\
\mathrm{~nm} \text { packing } \\
\mathrm{L} 1\end{array}$ & $\begin{array}{l}250 \times \\
4.6 \times 5\end{array}$ \\
\hline $\begin{array}{l}\text { Mobile } \\
\text { phase }\end{array}$ & $\begin{array}{l}\text { Methanol and } \\
\text { water }(1: 3)\end{array}$ & $\begin{array}{l}\text { Methanol } \\
\text { and Buffer } \\
(1: 19)\end{array}$ & Buffer \\
\hline Flow rate & $1.5 \mathrm{~mL} / \mathrm{min}$ & $2 \mathrm{~mL} / \mathrm{min}$ & $\begin{array}{l}1.0 \mathrm{~mL} / \\
\min \end{array}$ \\
\hline $\begin{array}{l}\text { Injection } \\
\text { volume }\end{array}$ & $10 \mu \mathrm{L}$ & $20 \mu \mathrm{L}$ & $5 \mathrm{~mL}$ \\
\hline Run time & 2.150 & 1.723 & 3.123 \\
\hline
\end{tabular}

Where $\mathbf{C}_{\mathbf{o}}$ is the initial concentration $((\mathrm{mg} / \mathrm{L}))$ of drug residue in sample before treatment and $\mathbf{C}_{\mathbf{e}}$ is the final concentration after treatment $(\mathrm{mg} / \mathrm{L})$.

\section{Preparation of Standards}

Standard stock solutions $(100 \mathrm{mg} / \mathrm{L})$ of amoxicillin, ascorbic acid and acetaminophen (paracetamol) were separately prepared in methanol and buffer (1:19) for amoxicillin; diluent (edetate disodium dehydrate and monobasic potassium phosphate) for ascorbic acid and methanol and water (1:3) for acetaminophen. Working standards of $0.5 \mathrm{mg} / \mathrm{mL}$ of amoxicillin (USP), $0.25 \mathrm{mg} / \mathrm{mL}$ ascorbic acid (USP) and $0.01 \mathrm{mg} / \mathrm{mL}$ acetaminophen (USP) were prepared by diluting appropriate aliquots of the stock solutions before each analytical run. All the solutions were stored at $4{ }^{\circ} \mathrm{C}$ in the dark.

\section{HPLC analysis}

Analyses of the three target drug compounds in the effluent were carried out quantitatively, using a Hitachi HPLC UV-VIS detector with Elite Lachrom software. All system parameters in HPLC were optimized in order to achieve high separation efficiency. Analyses of reference standard solutions were first run, to obtain the peak heights, retention time and area, after which the filtered samples which included untreated and treated wastewater samples were injected directly into the analytical column, and individually ran to yield the initial and final concentrations of the drug residues in the effluent, with reference to their retention times, peak heights and area respectively. Table 1 shows the different chromatographic conditions. In HPLC analysis, quantification was performed by comparing the area of chromatogram of spiked deionized water sample to that of wastewater sample at same retention time. Unspiked de-ionized water was used as a blank sample. The concentration of the analyte was calculated from the peak area.

\section{Results and Discussion}

Characterization of Nanomaterials 


\section{XRD}

The XRD patterns of synthesized ZnO NPs (Fig 1) show peaks corresponding to the crystal planes of (100), (002) and (101) of $\mathrm{ZnO}$ along with less noise which suggest that the synthesized sample belong to the hexagonal crystal lattice of the $\mathrm{ZnO}$ (JCPDS: 65-3411) [1213].The peaks observed were sharp, which indicates that compounds of only $\mathrm{ZnO}$ are present with minimum noise distortion or impurities. From the XRD data, it was found that the peaks are broad; suggesting that the crystallites have sizes in the nanometer range. The presence of other phases appears negligible as shown by the spectra. For the bio-ZnO (Fig. 2 ), the presence of $\mathrm{ZnO}$ peaks along with other peaks was observed in the spectrum which indicates that the $\mathrm{ZnO}$ formed were completely capped by the biomolecules of the leaf extract. The sharp and narrow diffraction peaks indicate that the product is well crystalline in nature. The calculated average crystallite sizes of both powder particles were about $9 \mathrm{~nm}$ for $\mathrm{ZnO}$ and 3 $\mathrm{nm}$ for bio- $\mathrm{ZnO}$.

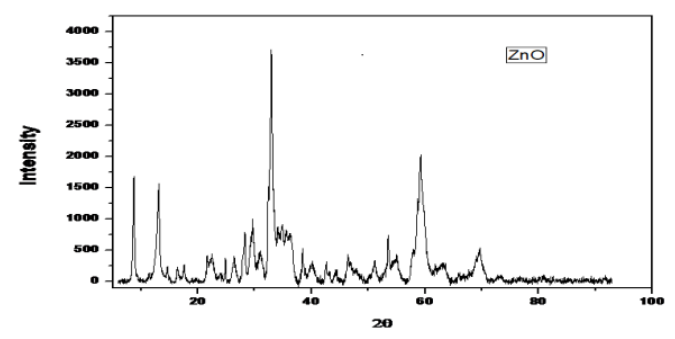

Fig. 1 XRD pattern of synthesized $\mathrm{ZnO}$ nanoparticles.

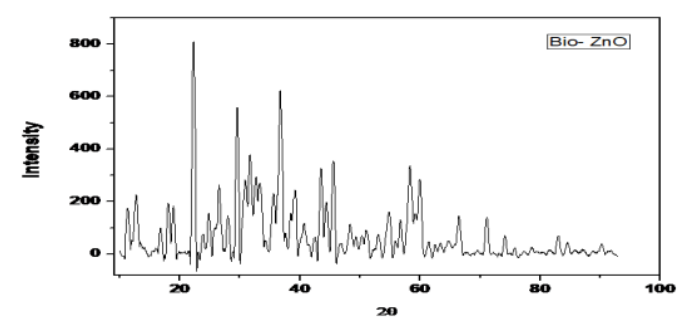

Fig. 2 XRD pattern of synthesized $S$. indica bio$\mathrm{ZnO}$ nanoparticles.

The XRD patterns of magnetite and biomagnetite (Figs. 3 and 4), show magnetite peaks at $2 \theta$ of $30.36,35.74,43.52,53.95,57.34$ and $63.0^{\circ}$ representing the corresponding indices of (220), (311), (400), (422), (511), and (440) respectively [14-15]. These were compatible with the standard data for $\mathrm{Fe}_{3} \mathrm{O}_{4}$ peaks (JCPDS: 19-0629). The XRD patterns of biomagnetite showed multiple peaks different from those of magnetite. This implies that the magnetite nanoparticles were mainly amorphous and capped by biomolecules extracted from Starchytarpheta indica. Hence the capping activity of the biomolecules might have prevented the detection of the iron oxides [16]. Another reason could also be the incomplete magnetic separation during biosynthesis. However, the very sharp and broad diffraction peaks indicate that the product is well crystalline in nature and this could account for the excellent adsorption performance observed for it. The average crystallite size of the prepared magnetite was $6.4 \mathrm{~nm}$ and that of bio-magnetite was 0.026 $\mathrm{nm}$.

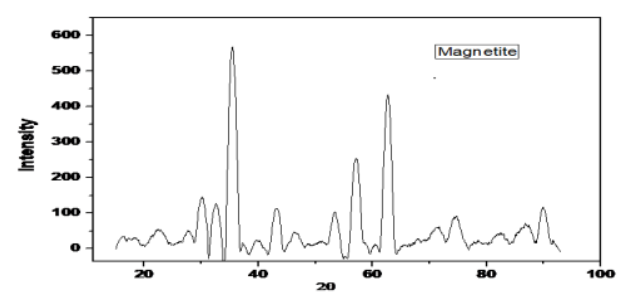

Fig. 3 XRD pattern of synthesized magnetite nanoparticles.

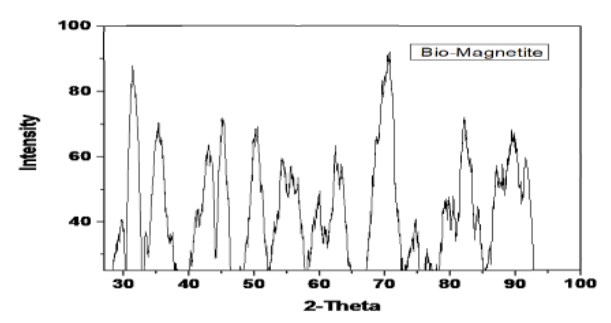

Fig. 4 XRD pattern of synthesized $S$. indica biomagnetite nanoparticles.

\section{FESEM}

Fig. 5 ( $a$ and $b$ ) show the SEM images of the $\mathrm{ZnO}$ nanoparticles at different magnifications which reveals that the $\mathrm{ZnO}$ nanoparticles had flake-like, and porous morphology with less aggregation [9]. The FESEM images of the bio$\mathrm{ZnO}$ nanoparticles with different magnifications are shown in Fig. $6(\mathrm{a} \& \mathrm{~b})$, which reveals that the bio-ZnO nanoparticles were spherical and globular with higher degree of agglomeration compared to $\mathrm{ZnO}$. These images also indicate 
the availability of nano-size pores and cracks on the surface of the nanoparticles.

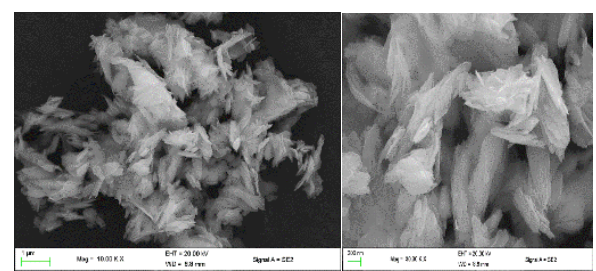

(a)

(b)

Fig. 5 (a\&b) SEM images of synthesized $\mathrm{ZnO}$ nanoparticles at magnifications of $1000 \mathrm{KX}$ and 3000KX.

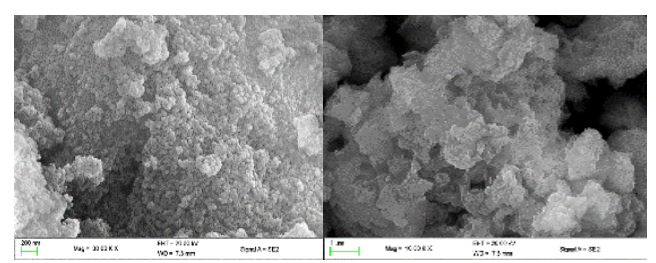

(a)

(b)

Fig. 6 (a\&b) FESEM images of S.indica synthesized BioZnO nanoparticles at magnifications of $3000 \mathrm{KX}$ and $10000 \mathrm{KX}$.

The SEM images of magnetite as shown in Fig. 7 (a\&b), reveals the presence of aggregates with different shapes and lengths, formed by agglomerated and almost spherical nanoparticles. The agglomeration may be due to magnetic dipole interactions between the particles [17]. The FESEM images of the biomagnetite nanoparticles (Fig. 8 (a and b)) revealed a sheet-like layer that appeared clumped and cracked, which might be due to the thickening properties of the snake weed $(S$. Indica) or the presence of hydroxyl groups from the extract [18]. Besides, the tendency of agglomeration is not surprising as the synthesized biomagnetite-NPs were very minute in size.

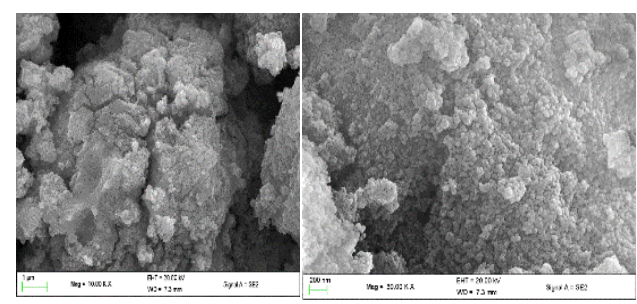

(a)

(b)
Fig. 7 (a\&b) FESEM images of synthesized nano magnetite at magnifications of $1000 \mathrm{KX}$ and $3000 \mathrm{KX}$.

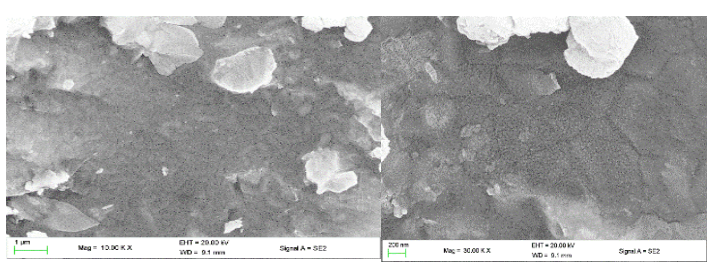

(a)

(b)

Fig. 8 (a\&b) FESEM images of synthesized nano bio-magnetite at at magnifications of $1000 \mathrm{KX}$ and $3000 \mathrm{KX}$.

\section{FTIR}

Fig. 9a shows the FTIR spectrum of $\mathrm{ZnO}$ nanoparticles synthesized using Zinc acetate and sodium carbonate as precursors. The peak at 468 $\mathrm{cm}^{-1}$ shows the characteristic absorption of $\mathrm{Zn}-$ $\mathrm{O}$ bond. The band at $676 \mathrm{~cm}^{-1}$ indicates the stretching vibrations of $\mathrm{ZnO}$ nanoparticle. The very intense double peaks at $1384 \mathrm{~cm}^{-1}$ and $1500 \mathrm{~cm}^{-1}$ are attributed to symmetrical and asymmetrical stretchings of the zinc carboxylate groups, and the absorption at $831 \mathrm{~cm}^{-1}$ is due to the lattice vibration of $\mathrm{CO}_{3}^{-2}$ [19]. This also verifies that $\mathrm{Na}_{2} \mathrm{CO}_{3}$ was one of the precursors used in the synthesis of $\mathrm{ZnO}$ nanoparticles. The weak double peaks at 2159 and $2026 \mathrm{~cm}^{-1}$ correspond to $\mathrm{C}-\mathrm{H}$ aldehydic stretching vibration. Broadband at around $3500 \mathrm{~cm}^{-1}$ is assigned to $\mathrm{O}-\mathrm{H}$ stretching mode of the hydroxyl group. This result is in good agreement with other works [20-21].

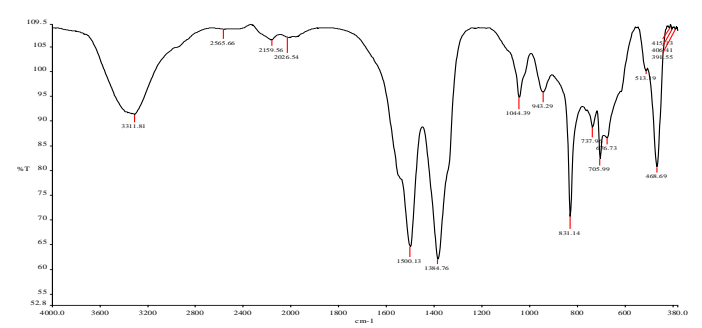

Fig. 9 FTIR spectrum of synthesized $\mathrm{ZnO}$ nanoparticles.

The FT-IR spectra of S.indica leaf extract is shown in Figure 10a. The absorption bands at wavelengths of 3761 and $3385 \mathrm{~cm}^{-1}$ correspond to $\mathrm{O}-\mathrm{H}$ stretching vibrations of polyols. Peaks at 2919 and $2850 \mathrm{~cm}^{-1}$ also represent $\mathrm{C}-\mathrm{H}$ 
aliphatic stretching of polyols. The sharp peak located at $1639 \mathrm{~cm}^{-1}$ represents $\mathrm{C}=\mathrm{C}$ stretching vibrations of aromatic rings. Stretching vibrations present at 1413 and $1381 \mathrm{~cm}^{-1}$ are associated with $\mathrm{O}-\mathrm{H}$ and $\mathrm{C}-\mathrm{OH}$ vibrations of polyols, respectively. Stretching vibrations located at $663 \mathrm{~cm}^{-1}$ is attributed to $\mathrm{N}-\mathrm{H}$ stretching vibrations of amines. The small peaks observed at 1730 and $1381 \mathrm{~cm}^{-1}$ may be attributed to $\mathrm{C}=\mathrm{O}$ stretching vibrations of carboxylic acid. These bands indicate the abundance of polyols (phenolic acid and flavonoids), terpenoids, and protein compounds in S.indica leaf extract, and may have largely contributed to the reduction of zinc salt to its nanoparticles.

FTIR spectra of biosynthesized ZnO NPs (Figure 10b) shows shifts in absorption bands at $3975 \mathrm{~cm}^{-1}, 3392 \mathrm{~cm}^{-1}, 2936$ and $2171 \mathrm{~cm}^{-1}$, 1634 and $1551 \mathrm{~cm}^{-1}, 1493$ and $1403 \mathrm{~cm}^{-1}, 836$ $\mathrm{cm}^{-1}$ and $472 \mathrm{~cm}^{-1}$ respectively. As earlier stated, the peaks in the region between 600 and $400 \mathrm{~cm}^{-}$ ${ }^{1}$ correspond to $\mathrm{Zn}-\mathrm{O}$, while the band at $472 \mathrm{~cm}^{-1}$ confirms stretching vibrations of zinc oxide NPs.

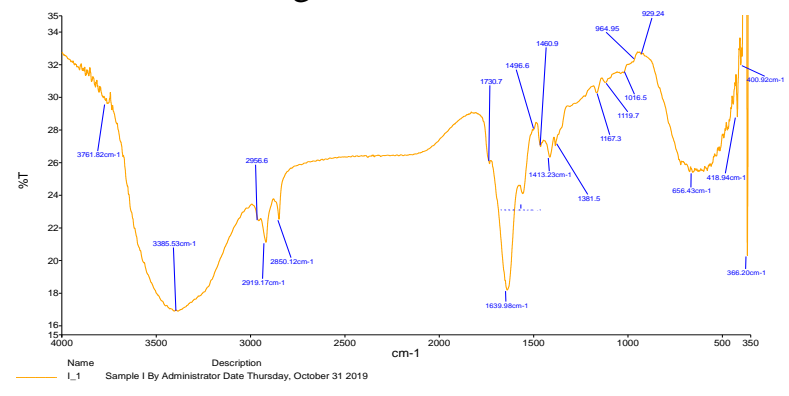

Fig. 10a FTIR spectrum of the chloroform extract of $S$. Indica.

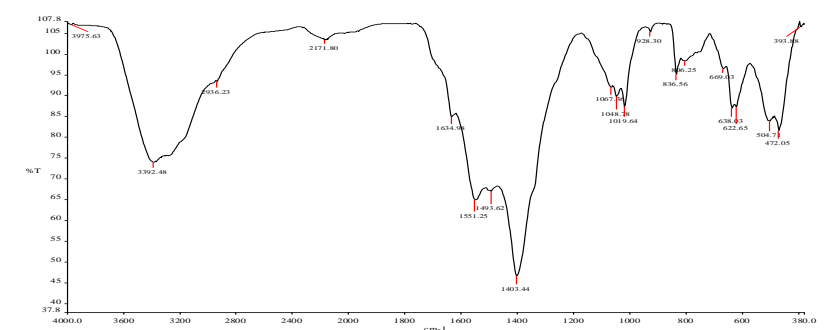

Fig. 10b FTIR spectrum of S. Indica synthesized $\mathrm{ZnO}$ nanoparticles.

In the FTIR spectrum of magnetite NPs (Fig 11), the presence of absorption bands at 449, 538 and $2352 \mathrm{~cm}-{ }^{1}$ corresponds to the magnetite $\left(\mathrm{Fe}_{3} \mathrm{O}_{4}\right)$ phase. The bands observed at $684 \mathrm{~cm}^{-1}$ corresponds to the intrinsic stretching vibration (Fetetra $\leftrightarrow \mathrm{O}$ ) of metal-oxygen at tetrahedral site whereas the band at $449 \mathrm{~cm}^{-1}$ corresponds to the stretching vibration (Feocta $\leftrightarrow$ O) of metaloxygen at octahedral site. Another related report showed that the characteristic absorption bands of the $\mathrm{Fe}-\mathrm{O}$ bond of bulk $\mathrm{Fe}_{3} \mathrm{O}_{4}$ were in 570 and $375 \mathrm{~cm}^{-1}$ [22]. However, in the synthesized magnetite, these two bands shifted to high wavenumbers of about 538 and $449 \mathrm{~cm}^{-1}$ respectively. The peaks at 1609 and $3120 \mathrm{~cm}^{-1}$ may be attributed to the stretching vibration of the $-\mathrm{OH}$ group of adsorbed water on the surface of the magnetite nanoparticles.

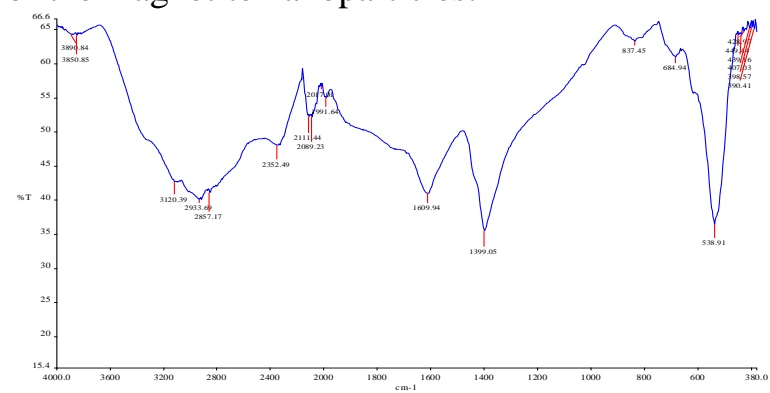

Fig. 11 FTIR spectrum of synthesized magnetite nanoparticles.

The FT-IR spectrum of S.indica leaves extract (Fig. 10a), indicated the presence of polyphenols and other biomolecules in the S.indica leaves extract and these biomolecules may have participated in the formation of magnetite nanoparticles.

The appearance of a new peak at $589 \mathrm{~cm}^{-1}$ (Fig.12) shows the typical characteristic absorption of magnetite nanoparticles. The broad bands at 3821 and $3295 \mathrm{~cm}^{-1}$ are assigned to $\mathrm{O}-\mathrm{H}$ (polyphenolic group) stretching, the weak band at $2158 \mathrm{~cm}^{-1}$ corresponds to $\mathrm{C}-\mathrm{H}$ stretching and a band at around $1582 \mathrm{~cm}^{-1}$ can be attributed to the $\mathrm{C}=\mathrm{C}$ ring stretching in polyphenols. The band at $1351 \mathrm{~cm}^{-1}$ corresponds to the $\mathrm{C}-\mathrm{N}$ stretching vibrations while the medium peak at $1065 \mathrm{~cm}^{-1}$ may be attributed to the stretching vibration of $\mathrm{C}-\mathrm{O}-\mathrm{C}$. Several other peaks in the spectral range $800-1800 \mathrm{~cm}^{-1}$ may also be attributed to the polyphenols that were likely present at the surface of iron nanoparticles. 


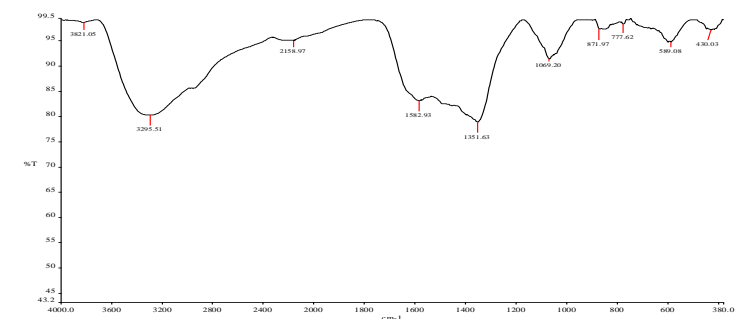

Fig. 12 FTIR spectrum of S. Indica synthesized bio-magnetite nanoparticles.

\section{Analysis of pharmaceutical effluent \\ Analysis of the pharmaceutical effluent revealed the presence of three pharmaceutical residues (amoxicillin, acetaminophen and ascorbic acid) in various concentrations (Table 2). Amoxicillin had the highest concentration $(341.71 \mathrm{mg} / \mathrm{l}$ ), while the least concentration was observed for acetaminophen $(2.5998 \mathrm{mg} / \mathrm{l})$.}

Table 2 mean concentration values of pharmaceutical residues

Target compounds Initial effluent pharmaceutical residue average concentration $(\mathrm{mg} / \mathrm{L})$

\begin{tabular}{ll}
\hline Amoxicillin & $341.71 \pm 0.001$ \\
Acetaminophen & $2.60 \pm 0.000$ \\
Ascorbic acid & $212.51 \pm 0.001$ \\
\hline
\end{tabular}

Values $=$ Mean of triplicate values \pm Standard error of mean

Treatment of pharmaceutical wastewater with the prepared nanoparticles

The adsorption of pharmaceuticals by adsorbents is mostly influenced by their physical/chemical properties [23], hence treatment of the effluent with the synthesized nanoparticles generally showed insignificant removal of amoxicillin, with $\mathrm{ZnO}$ and bio-magnetite nanoparticles having removal efficiencies of $49.73 \%$ and $16.72 \%$ respectively. Negative removal efficiencies and increased concentrations of amoxicillin were observed when the effluent was treated with Bio- $\mathrm{ZnO}$ and magnetite (Table 3). This observed increase in concentration may have resulted from (i) amoxicillin's specific characteristics and persistence nature, for instance its water soluble nature and the low $\mathrm{K}_{\mathrm{ow}}$ value (0.84) prevents amoxicillin from getting adsorbed onto the nano-adsorbents. Another reason could be the deconjugation of conjugated metabolites during the adsorption process [24]. Furthermore, a change in the adsorption behavior of the target compounds to the nanoparticles during treatment processes may influence their ratio in the treated and untreated water. Then finally $\mathrm{pH}$ conditions may also affect the kinetic behavior of the compounds. Similarly, Minh et al. (2009) [25] reported very high levels of amoxicillin (1300-1660 $\mathrm{ng} \mathrm{L}^{-1}$ ) in the treated effluents of Hong Kong, and Shishir et al. (2011) [26] reported the removal efficiencies of antibiotics as varying between -11.2 and $69 \%$.

Treatment with the bio-adsorbents (bio- $\mathrm{ZnO}$ and bio-magnetite) showed better removal of acetaminophen, with removal efficiencies of 93.59 and $92.81 \%$ respectively when compared with $\mathrm{ZnO}$ and magnetite, which had removal efficiencies of 87.43 and $65.07 \%$ (Table 3). High removal efficiencies for acetaminophen have continuously been observed by other researchers [27-28]. This is attributable primarily to the high adsorption sites of the nanoparticles, or microbial degradation, where primary treatment occurs for wastewater treatment plants [29].Therefore the synthesized nanoparticles are observed to be good adsorbents for the elimination of acetaminophen from pharmaceutical effluents.

From Table 3, ascorbic acid presented high removal efficiencies after effluent samples were treated with the synthesized nanoparticles. Highest removal efficiencies $(100 \%)$ were observed for magnetite and bio-magnetite, while treatment with bio- $\mathrm{ZnO}$ showed relatively lower percentage removal efficiency of $54.35 \%$. Appreciable percentage removal efficiency of $88.52 \%$ was obtained for $\mathrm{ZnO}$ nanoparticles, signifying that the nanoparticles can effectively reduce the concentration of ascorbic acid in industrial effluents. 
Table 3 Concentrations of pharmaceuticals $\left(\mathrm{mg} \mathrm{mL}^{-1}\right)$ in wastewater sample after treatment with nano-adsorbents

\begin{tabular}{|c|c|c|c|c|c|c|}
\hline $\begin{array}{l}\text { Detected Target } \\
\text { Compounds }\end{array}$ & $\begin{array}{l}\mathrm{ZnO} \\
\mathrm{C}_{\mathrm{o}} \\
(\mathrm{mg} / \mathrm{L})\end{array}$ & $\mathrm{C}_{\mathrm{e}}(\mathrm{mg} / \mathrm{L})$ & $\% \mathrm{R}$ & $\begin{array}{l}\text { Bio-ZnO } \\
\mathrm{C}_{0}((\mathrm{mg} / \mathrm{L})\end{array}$ & $\mathrm{C}_{\mathrm{e}}(\mathrm{mg} / \mathrm{L})$ & $\% \mathbf{R}$ \\
\hline Amoxicillin & 341.71 & 171.78 & 49.73 & 341.71 & 400.35 & -17.16 \\
\hline Acetaminophen & 2.60 & 0.33 & 87.43 & 2.60 & 0.17 & 93.59 \\
\hline Ascorbic acid & 212.51 & 24.40 & 88.52 & 212.51 & 97.02 & 54.35 \\
\hline $\begin{array}{l}\text { Total pharmaceutical } \\
\text { compounds }\end{array}$ & 556.82 & 196.50 & 64.71 & 556.82 & 497.53 & 10.65 \\
\hline
\end{tabular}

Table 3 Concentrations of pharmaceuticals $\left(\mathrm{mg} \mathrm{mL}^{-1}\right)$ in wastewater sample after treatment with nano-adsorbents (cont'd)

\begin{tabular}{|c|c|c|c|c|c|c|}
\hline $\begin{array}{l}\text { Detected Target } \\
\text { Compounds }\end{array}$ & $\begin{array}{l}\text { Mag } \\
\text { Co }_{0} \\
(\mathrm{mg} / \mathrm{L})\end{array}$ & $\begin{array}{l}\mathrm{C}_{\mathrm{e}} \\
(\mathrm{mg} / \mathrm{L})\end{array}$ & $\% \mathbf{R}$ & $\begin{array}{l}\text { Bio-mag } \\
C_{0}(\mathrm{mg} / \mathrm{L})\end{array}$ & $\mathrm{C}_{\mathrm{e}}(\mathrm{mg} / \mathrm{L})$ & $\% \mathbf{R}$ \\
\hline Amoxicillin & 341.71 & 396.35 & \multirow{2}{*}{$\begin{array}{l}-15.99 \\
65.07\end{array}$} & 341.71 & 284.22 & 16.82 \\
\hline Acetaminophen & 2.60 & 0.9081 & & 2.5998 & 0.1868 & 92.81 \\
\hline Ascorbic acid & 212.51 & N.D & 100 & 212.51 & N.D & 100 \\
\hline $\begin{array}{l}\text { Total pharmaceutical } \\
\text { compounds }\end{array}$ & 556.82 & 397.26 & 28.66 & 556.82 & 284.41 & 48.92 \\
\hline
\end{tabular}

Percentage removals of the individual and total pharmaceutical residues in the effluent by the nanoparticles are presented in the charts in Figs. 13 and 14. ZnO showed better removal of amoxicillin in comparison with other nanoparticles as seen in Fig. 13. The percentage removal efficiencies for acetaminophen followed the order: bio-ZnO > bio-magnetite > $\mathrm{ZnO}>$ magnetite. Ascorbic acid was also well adsorbed by the nanoparticles, with exception of bio-ZnO that showed less than $60 \%$ removal efficiency.

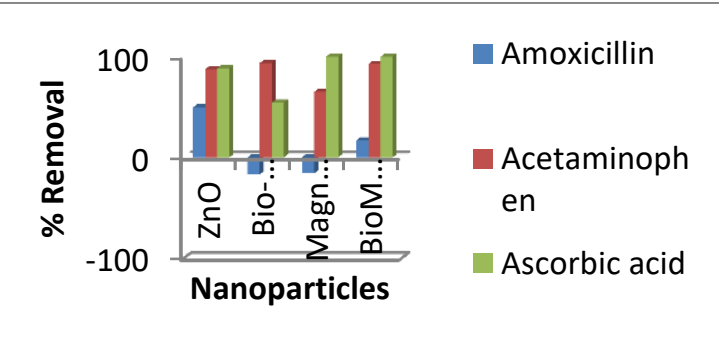

Fig. 13 Percentage removals of the individual pharmaceutical residues in the effluent by the NPs.

Fig. 14 shows the total pharmaceutical residues removed by the nanoparticles. As seen from the figure, $\mathrm{ZnO}$ nanoparticles generally had the highest removal efficiency $(64.71 \%)$, followed by the bio-magnetite nanoparticles (48.92\%). Total removal of pharmaceutical residues by bio- $\mathrm{ZnO}$ and magnetite nanoparticles were not 
very significant, as the removal efficiencies were below $30 \%$.

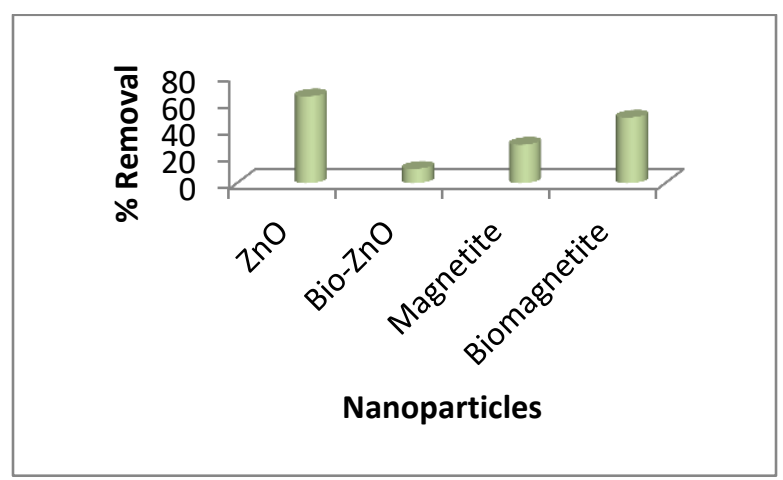

Fig. 14 Total removal of pharmaceutical residues by in the effluent by the NPs.

\section{Conclusion}

Green and chemical synthesis of $\mathrm{ZnO}$ and magnetite nanoparticles can be done using their salts as precursors and the leaf extract of Starchytarpheta indica for the green synthesis. The synthesized nanoparticles were characterized by XRD, FTIR and FESEM and further applied in the treatment of pharmaceutical effluent, where $\mathrm{ZnO}$ and biomagnetite nanoparticles were observed to have shown better removal efficiencies for amoxicillin, than the bio- $\mathrm{ZnO}$ and magnetite. For the removal of acetaminophen, the synthesized bio-nanoparticles of $\mathrm{ZnO}$ and magnetite displayed better performance in comparison with the chemically synthesized nanoparticles. Magnetite and bio-magnetite nanoparticles had optimum removal effect for ascorbic acid, while $\mathrm{ZnO}$ showed higher removal of ascorbic acid than the bio- $\mathrm{ZnO}$. Generally, the synthesized $\mathrm{ZnO}$ and biomagnetite nanoparticles displayed better percentage removal of total target pharmaceutical residues than the other synthesized nanoparticles, with $\mathrm{ZnO}$ having the most effect

\section{References}

[1] B. Petrie, R. Barden and B. KasprzykHordern (2015), A review on emerging contaminants in wastewaters and the environment: current knowledge, understudied areas and recommendations for future monitoring. Water Resources 72, 3-27.
[2] K. Caballero-Gallardo, J. Olivero-Verbel, and J.L. Freeman (2016), Toxicogenomics to Evaluate Endocrine Disrupting Effects of Environmental Chemicals Using the Zebrafish Model. Current genomics, 17(6), 515-527.

[3] D. Balabanič, A. Krivograd Klemenčič, and A. ZdravVestn. (2018), Endocrinedisrupting chemicals and male reproductive health: a review. 87(1-2), 69-70.

[4] E. E. Chang, J. C. Wan, H. Kim, C. H., Liang, Y. D., Dai, and P. C. Chiang (2015), Adsorption of Selected Pharmaceutical Compounds onto Activated Carbon in Dilute Aqueous Solutions Exemplified by Acetaminophen, Diclofenac, and Sulfamethoxazole. The Scientific World Journal, 1-11. doi:10.1155/2015/186501.

[5] B. Tiwari, B. Sellamuthu, Y. Ouarda, P. Drogui, R. D Tyagi, and G. Buelna (2017), Review on fate and mechanism of removal of pharmaceutical pollutants from wastewater using biological approach. Bioresource Technology, 224, 1-12.

[6] M. M. Khin, A. S. Nair, V. J Babu, R. Murugan, and S. Ramakrishna (2012), A review on nanomaterials for environmental remediation. Energy \& Environmental Science, 5(8), 8075.

[7] O. Fouad, A. R Khder, Q. Dai and M. S. El-Shall (2011), Structural and catalytic properties of $\mathrm{ZnO}$ and $\mathrm{Al}_{2} \mathrm{O}_{3}$ nanostructures loaded with metal nanoparticles. Journal of Nanoparticle Research, 13, 7075.

[8] R. M. Mohamed, I. A. Mkhalid, E. S. Baeissa, and M. A Al-Rayyani (2012 Photocatalytic Degradation of Methylene Blue by $\mathrm{Fe} / \mathrm{ZnO} / \mathrm{SiO}_{2}$ Nanoparticles under Visible light. Journal of Nanotechnology, 12, 5.

[9] G. Sangeetha, S. Rajeshwari, and R. Venckatesh (2011), Green synthesis of zinc oxide nanoparticles by Aloe barbadensis miller leaf extract: structure and optical properties. Materials Research Bulletin, 46 (12), 25602566.

[10] D. Gnanasangeetha and D. S Thambwani. (2013), Biogenic production of zinc oxide nanoparticles using Acalypha indica. Journal of Chemical, Biological and Physical Sciences, 1, 238-246.

[11] M. I. Khalil (2015), Co-precipitation in aqueous solution synthesis of magnetite 
nanoparticles using iron (III) salts as precursors. Arabian Journal of Chemistry, 8 (2), 279-284.

[12] H. R. Mirzaei, H. Pourghadamyari, M. Rahmati, A. Mohammadi, J. S. Nahand, A. Rezaei, and J. Hadjati (2018), Gene-knocked out chimeric antigen receptor (CAR) $\mathrm{T}$ cells: Tuning up for the next generation cancer immunotherapy. Cancer Letters, 423( 9) , $5-104$.

[13] K. Elumalai and S. Velmurugan (2015), Green synthesis, characterization and antimicrobial activities of zinc oxide nanoparticles from the leaf extract of Azadirachta indica (L.). Applied Surface Science, 345, 329-336.

[14] R. M. Cornwell and U. Schwertmann (2003), The Iron Oxides: Structure, Properties, Reactions, Occurrences and Uses. WileyVCHGmbh\&Co. Weinheim pp. 69-78.

[15] L. Xu, J. Feng, J. Li, X. Liu, and S. Jiang (2012), Graphene oxide bonded fused-silica fiber for solid-phase microextraction-gas chromatography of polycyclic aromatic hydrocarbons in water. Journal of Separation Science, 35(1), 93-100.

[16] F. Luo, Z. Chen, M. Megharaj and R. Naidu (2014), Biomolecules in grape leaf extract involved in one-step synthesis of iron-based nanoparticles. RSC Advances, 4, 53467-53474.

[17] W. Eldin, L. Chuan and F. Ruili, (2012), Agglomeration of magnetic nanoparticles. Journal of Chemical Physics, 136, 124109.

[18] S. Venkateswarlu and M.Yoon (2015), Surfactant-free green synthesis of $\mathrm{Fe}_{3} \mathrm{O}_{4}$ nanoparticles capped with 3, 4dihydroxyphenethylcarbamodithioate: stable recyclable magnetic nanoparticles for the rapid and efficient removal of $\mathrm{Hg}$ (II) ions from water. Journal of Chemical Society Dalton Trans 44(42), 18427-18437.

[19] Y. Wang, C. Zhang, S. Bi and G. Luo (2010), Preparation of $\mathrm{ZnO}$ nanoparticles using the direct precipitation method in a membrane dispersion micro-structured reactor. Powder Technology, 202, 130-136.

[20] A. K., Zaka, W. H. Abd. Majid, M. Darroudi, and R. Yousefi (2011), Material Letters 65, 70-73.
[21] R. Y. Hong, J. H. Li, L. L. Chen, D. Q. Liu, H. Z. Li, Y. Zheng, and J. Ding (2009), Synthesis, surface modification and photocatalytic property of $\mathrm{ZnO}$ nanoparticles. Powder Technology, 189, 426-432.

[22] M. Ma, Y. Zhang, W. Yu, H. Shen, H. Zhang and G. Ning, (2003), Preparation and Characterization of Magnetite Nanoparticles Coated by Amino Silane. Colloids and Surfaces A: 212, 219-226.

[23] Y. C. Chang, S. W. Chang and D. H. Chen (2006), Magnetic chitosan nanoparticles: Studies on chitosan binding and adsorption of $\mathrm{Co}$ (II) ions. Reactive \& Functional Polymer 66, 335341.

[24] X. S. Miao and B. G. Koenig (2002), Analysis of acidic drugs in the effluents of sewage treatment plants using liquid chromatography-electrospray ionization tandem mass spectrometry. Journal of Chromatography A, 952(1-2): 139-147.

[25] T. B. Minh, H. W. Leung, I. H. Loi, W. H. Chan, M. K. So, J. Q. Mao, J. C. Choi, W. Lam and B. J. Richardson (2009), Antibiotics in the Hong Kong metropolitan area: ubiquitous distribution and fate in Victoria harbour, Marine Pollution Bulletin, 58(7): 1052-1062.

[26] K. B. Shishir, W. K. Hyeong, O. JeongEun and P. Hung-Suck (2011), Occurrence and removal of antibiotics, hormones and several other pharmaceuticals in wastewater treatment plants of the largest industrial city of Korea. Science of the Total Environment, 409, 43514360.

[27] O. A. H. Jones, N. Voulvoulis and J. N. Lester (2007), Environmental Pollution 145(3):738-744.

[28] J. $\quad$ T. $\quad$ Yu, E. J. Bouwer and M. Coelhan (2006), The

occurrence and removal of selected pharmaceutical compounds in a sewage treatment works utilising activated sludge treatment. Agricultural Water Management 86(12), 72-80.

[29] A. Joss, E. Keller, A. C. Alder, A. Göbel, C. S. McArdell, T. Ternes, and H. Siegrist (2006), Removal of pharmaceuticals and fragrances in biological wastewater treatment. Water Research, 39(14): 3139-3152. 